\title{
PERÚ Y LA ESTRATEGIA ARMADA EN LOS AÑOS SESENTA: LA REACTUALIZACIÓN DE UN DEBATE
}

\author{
MARTÍN MANGIANTINI (Instituto Ravignani - CONICET / UBA) \\ Facultad de Filosofía y Letras / Universidad de Buenos Aires \\ Becario del Consejo Nacional de Investigaciones Científicas y Técnicas / Instituto Ravignani \\ (25 de Mayo $221,2^{\circ}$ piso, $\left.\mathrm{CABA}\right)$ \\ martinmangiantini@gmail.com
}

\section{Resumen}

A principios de los años sesenta, la organización trotskista argentina Palabra Obrera decidió el envío de tres militantes al Perú con el objetivo de construcción e inserción política en un contexto de importante convulsión social, principalmente a partir de la toma de tierra y la sindicalización campesina en la región del Cuzco. La puesta en práctica de acciones armadas por parte de este grupo generó un proceso de discusión y debate que, recientemente, se trajo a colación a raíz de una serie de nuevos insumos documentales. Es objetivo de este artículo analizar este hecho a la luz de estas flamantes herramientas de discusión.

\section{Palabras Claves}

Lucha armada - Trotskismo - Movimiento campesino - Guevarismo

\begin{abstract}
At the beginning of the sixties, the Trotskyist Argentine organization Palabra Obrera (Working Word) decided to send three militants to Peru with the aim of construction and of political insertion in a context of important social convulsion, principally from the capture of land and the rural unionization in the region of the Cuzco. The implementation of armed actions by this group generated a process of discussion and debate that, recently, was brought to collation immediately after a series of new documentary inputs. It is the aim of this article to analyze this fact in the light of these brand new discussion tools.
\end{abstract}

\section{Keywords}

Armed Struggle - Trotskyism - Peasant Movement - Guevarism 


\title{
PERÚ Y LA ESTRATEGIA ARMADA EN LOS AÑOS SESENTA: LA REACTUALIZACIÓN DE UN DEBATE
}

\author{
MARTÍN MANGIANTINI (Instituto Ravignani - CONICET / UBA)
}

martinmangiantini@gmail.com

A comienzos de la década del sesenta, Perú experimentó un destacado ascenso insurreccional en la región del Cuzco, prioritariamente en la provincia de La Convención y en el distrito de Lares (en la provincia de Calca). Los efectos del triunfo revolucionario cubano de 1959 dieron lugar a un proceso de radicalización ideológica de diversos actores político-sociales de la sociedad peruana siendo una de sus expresiones más relevantes el papel sostenido por el campesinado cuzqueño bajo el liderazgo de Hugo Blanco ${ }^{1}$, un dirigente formado académica y políticamente en la Argentina. Proveniente de las capas medias peruanas, estudió abogacía en la Universidad de La Plata y se proletarizó en los frigoríficos Armour y Swift de Berisso en donde desarrolló su militancia sindical involucrándose, simultáneamente, con la corriente trotskista dirigida por Nahuel Moreno, en ese momento estructurada bajo la nomenclatura de Palabra Obrera ${ }^{2}$. Blanco vivió en la Argentina hasta 1958 cuando retornó a su país natal y comenzó a participar del Partido Obrero Revolucionario (POR), una organización trotskista hermanada internacionalmente con la estructura argentina antes referida. En diciembre de 1961, este partido confluyó con diversos militantes independientes, referentes del PC-Leninista y una fracción del Partido Comunista de Perú dando forma al denominado Frente de Izquierda Revolucionaria (FIR).

Más allá de su trayectoria preexistente en la producción industrial, tiempo después de su retorno al Perú, Blanco se trasladó al Cuzco y, tras una experiencia sindical entre los trabajadores vendedores de periódicos, inició un proceso de organización política del campesinado. En el marco de una mayoritaria población indígena sometida a condiciones de trabajo precarias, enquistadas en estructuras y relaciones de producción con notorios resabios feudales, el

\footnotetext{
${ }^{1}$ Sobre el proceso político peruano en los años sesenta: Hobsbawm, Eric, Rebeldes primitivos. Estudio sobre las formas arcaicas de los movimientos sociales en los siglos XIX y XX, Barcelona, Ariel, 1974; Camarero, Hernán, "Hugo Blanco y el levantamiento campesino en la región del Cuzco (1961-1963)", Periferias. Revista de Ciencias Sociales, Número 8, 2000; Napurí, Ricardo, Pensar América Latina. Crónicas autobiográficas de un militante revolucionario, Buenos Aires, Ediciones Herramienta, 2009; Craig, Wesley, El movimiento campesino en la Convención, Perú. La dinámica de una organización campesina, Lima, Instituto de Estudios Peruanos, 1968. Para profundizar sobre la figura de Hugo Blanco: Villanueva, Víctor, Hugo Blanco y la rebelión campesina, Lima, Juan Mejia Baca, 1967; Blanco, Hugo, Tierra o muerte. Las luchas campesinas en Perú, México, Siglo XXI, 1972; Blanco, Hugo, Nosotros los indios, Buenos Aires, Herramienta, 2010.

2 Palabra Obrera fue la organización continuadora de una corriente trotskista existente en Argentina desde la década del cuarenta. Encabezada por Nahuel Moreno, surgió con la creación del Grupo Obrero Marxista, impulsado por un puñado de jóvenes que buscaron una inserción política en la clase obrera porteña y del Gran Buenos Aires durante el surgimiento del peronismo. Tras una cierta expansión, este grupo se convirtió en Partido Obrero Revolucionario para, posteriormente, integrarse al Partido Socialista de la Revolución Nacional, un desprendimiento del viejo PS. Luego del golpe de Estado que derribó al gobierno peronista en 1955, la principal acción de esta corriente se desenvolvió dentro del movimiento obrero que resistió a la Revolución Libertadora. Acorde a esta línea, impulsó el Movimiento de Agrupaciones Obreras con el objetivo de construcción de una tendencia sindical y clasista independiente y, desde 1957, comenzó a practicar el "entrismo" en el movimiento peronista con la pretensión de influir en un viraje ideológico de sus integrantes hacia posiciones de izquierda. Con esta orientación, esta corriente comenzó a editar el periódico Palabra Obrera, utilizado para relacionarse con los diversos sectores de la vanguardia fabril. Tal fue la importancia de esta herramienta de difusión que al propio grupo se lo empezó a conocer y denominar con ese nombre. Su existencia data hasta 1964 cuando, ya culminada la experiencia del "entrismo", se produjo la fusión entre Palabra Obrera y el Frente Revolucionario Indoamericano Popular (FRIP) dando origen, un año después, al Partido Revolucionario de los Trabajadores (PRT).
} 
movimiento liderado por Hugo Blanco realizó la novedosa tarea de forjar un proceso de sindicalización del trabajador rural cuzqueño. Entre las acciones colectivas desarrolladas se destacó la toma de terrenos. Ella incluía la obstaculización de la producción de las propiedades latifundistas pero, al mismo tiempo, la posibilidad del campesinado de dedicarse a trabajar en el terreno designado a su persona. Como señala el trabajo de Camarero, tal combinación de elementos llevaba a un proceso de concientización por parte del trabajador que, en definitiva, planteaba la problemática de la propiedad agraria ${ }^{3}$.

En el marco de esta ascendente conflictividad y de la gestación de embrionarias instancias organizativas, con los objetivos de profundizar tal radicalización y de pugnar por la ligazón internacional entre diversas estructuras partidarias, en junio de 1961, la organización argentina Palabra Obrera envió a Perú a sus militantes Daniel Pereyra (“Alonso”), Eduardo Creus y José Martorell. Rápidamente, se desató una polémica entre la dirigencia de Palabra Obrera y sus propios militantes, especialmente con Daniel Pereyra, acerca del modo de inserción y de la estrategia a desarrollar en el proceso político peruano. Escaso tiempo después, la conducción de Palabra Obrera consideró que el accionar de su militancia radicada en Perú había tomado un giro táctico erróneo acorde a una concepción que primaba el accionar armado de una vanguardia revolucionaria por sobre aquellas iniciativas de masas que, en tal coyuntura, se producían cotidianamente como, por ejemplo, las tomas de tierras y la sindicalización campesina, ambas referenciadas en la figura de Blanco. Las diferencias teórico-conceptuales y estratégicas que derivaron de este proceso se vieron materializadas en una serie de documentos e intercambio de correspondencia entre dirigentes que se convierten en un ejemplo del clima de época existente en las inmediatas postrimerías de la Revolución Cubana en toda América Latina al interior de las organizaciones revolucionarias.

Historiográficamente resulta por lo menos llamativo y cobra interés el hecho de que, recientemente, estas discusiones sostenidas en el seno de una vanguardia política en los tempranos años sesenta hayan cobrado visibilidad a partir de una serie de producciones que, más de medio siglo después, vuelven a traer tales debates al presente, en algunos casos otorgándoles significados y sentidos diferentes a sus percepciones originales. En relación con ello, en el año 2014, el propio Daniel Pereyra editó una autobiografía en la que reflexiona sobre su derrotero militante y dedica un considerable espacio a la polémica experiencia peruana ${ }^{4}$. Más recientemente, el Centro de Estudios Humanos y Sociales (CEHUS) reeditó el trabajo de Nahuel Moreno Perú: Dos estrategias ${ }^{5}$. Originalmente publicado en 1964, se trata de una compilación (durante años inaccesible en forma completa) que reúne las diversas cartas que, entre 1961 y 1963, Nahuel Moreno dirigió a Daniel Pereyra, a Hugo Blanco y a otros actores involucrados en este proceso de conflictividad política y social del Perú. Esta producción posee el valor de compilar documentos elaborados al calor de los acontecimientos, con sus percepciones coetáneas y sin intermediaciones dadas por aquellos balances construidos décadas después del acontecer de los hechos. Por último, completa esta tríada de producciones referidas, directa o indirectamente, a esta temática un reciente documental dirigido por Marcel Gonnet Wainmayer, titulado El trotskismo bárbaro ${ }^{6}$, referido a la vida personal y a diversos momentos de la trayectoria política de Nahuel Moreno. Este material audiovisual dedica un espacio de jerarquía al accionar de esta corriente en Perú en los años sesenta y, específicamente, a las controvertidas acciones allí desarrolladas y referidas en las mencionadas polémicas.

\footnotetext{
3 Camarero, Hernán, "Hugo Blanco..." Op. Cit.

${ }^{4}$ Pereyra, Daniel, Memorias de un militante internacionalista, Buenos Aires, CEICS-Ediciones RyR, 2014.

${ }^{5}$ Moreno, Nahuel, Perú: dos estrategias. La rebelión campesina encabezada por Hugo Blanco y la polémica con el putschismo (19611963), Buenos Aires, CEHUS, 2015.

${ }^{6}$ El trotskismo bárbaro, dirigido por Marcel Gonnet Wainmayer, Argentina, 2015, Cinema do Polvo productora.
} 


\section{Trotskismo y castrismo como paradigmas en diálogo y tensión}

El triunfo de la Revolución Cubana generó en la izquierda revolucionaria de toda América Latina redefiniciones y discusiones en torno a los paradigmas organizativos y metodológicos hasta entonces vigentes. Dicho proceso ponía de manifiesto un nuevo tipo de esquema políticoorganizativo, el guevarismo, el cual recaía en la construcción de organizaciones simultáneamente políticas y militares, la primacía del campesinado como sujeto revolucionario y punto de partida de una radicalización social más amplia y la guerra de guerrillas como estrategia central para forjar la transformación revolucionaria de la sociedad. Su triunfo supuso, paralelamente, la aparición de una concepción de construcción política alternativa al tradicional esquema leninista proveniente de la victoria bolchevique. En este sentido, la construcción de partidos políticos que pugnaran por la inserción en los organismos de la clase obrera, la estrategia insurreccional y la metodología del centralismo democrático al interior de un partido, entraron en discusión por diversos sectores de la vanguardia revolucionaria latinoamericana. Este tipo de debate incluyó a un abanico de organizaciones en el que también se incluyen aquellos partidos políticos encuadrados dentro de las corrientes trotskistas.

Las direcciones del trotskismo internacional no se mostraron ajenas al proceso revolucionario en curso. Michel Pablo, dirigente trotskista posterior a la Segunda Guerra Mundial, se convirtió en un entusiasta defensor de la Revolución Cubana y del liderazgo de Fidel Castro, a quien caracterizó como un "trotskista natural". Por su parte, para el principal partido trotskista norteamericano, el Socialist Worker Party (SWP), la Revolución Cubana se convertía en la solución al problema de la dirección revolucionaria en América del Norte y Latinoamérica y proponía la conformación en Cuba de un partido marxista revolucionario bajo la dirección de Castro, al cual los trotskistas cubanos debían integrarse. Con concepciones similares, el Partido Obrero Revolucionario (POR) de Chile, en muestra de adhesión a la estrategia de la guerrilla cubana, se disolvió para formar parte del Movimiento de Izquierda Revolucionaria (MIR) en conjunto con otras corrientes políticas e ideológicas. Simultáneamente, el Partido Obrero Revolucionario (POR) de Bolivia, bajo la dirección de Hugo González Moscoso, defendió el desarrollo de guerrillas urbanas y rurales en toda América Latina como estrategia válida aplicable a todos los países subdesarrollados. Posteriormente, referentes internacionales como Ernest Mandel y Livio Maitán incorporaron concepciones distantes al "trotskismo ortodoxo", tales como la revolución campesina por la vía militar, la teoría maoísta del cerco a la ciudad o, concretamente, la estrategia del "foquismo". Contrariamente, otros dirigentes como el francés Pierre Lambert, se manifestaron inicialmente distantes con la Revolución Cubana y esbozaron sus críticas caracterizando la ausencia de rupturas significativas con su concreción.

A modo estructural, desde 1953, la IV Internacional se dividió en dos agrupamientos diferentes: por un lado, el Secretariado Internacional (SI), en donde participaban Ernest Mandel (Bélgica), Pierre Frank (Francia) y Livio Maitán (Italia); por el otro lado, el Comité Internacional (encabezado por el SWP de los EE.UU.) en el que militaban Pierre Lambert (Francia), Gerry Healy (Inglaterra) y el argentino Nahuel Moreno. El impacto que generó la Revolución Cubana y la dicotomía entre quienes caracterizaban a Cuba como el primer estado obrero latinoamericano y quienes esgrimieron la perdurabilidad del capitalismo en la isla, culminó con una reunificación de la IV Internacional en manos de quienes defendían el proceso cubano dando nacimiento al denominado Secretariado Unificado (SU) de la IV Internacional. Sin embargo, esta restructuración no eliminó el debate que, en torno a este proceso, continuó desarrollándose en el seno del trotskismo internacional en los años posteriores ${ }^{7}$.

\footnotetext{
7 Alexander, Robert J, Trotskyism in Latin America, Stanford University, Hoover Institution Press, 1973; Bensaï, Daniel, Trotskismos, Portugal, Ediçŏes Combate, 2008; Callinicos, Alex, Trotskyism, Buckingham, Open University Press, 1990; Coggiola, Osvaldo, Historia del trotskismo en Argentina y América Latina, Buenos Aires, Ediciones RyR, 2006.
} 
En Argentina, la Revolución Cubana impactó de diverso modo en las organizaciones revolucionarias y en su intelectualidad dando lugar a una importante cantidad de agrupamientos que pretendían posicionarse a la izquierda de los tradicionales Partidos Socialista y Comunista. La radicalización de amplios sectores del movimiento estudiantil ${ }^{8}$, la aparición de nuevos grupos como Vanguardia Revolucionaria (de Juan Carlos Portantiero), estructuras simultáneamente políticas y militares como el fugaz Ejército Guerrillero del Pueblo de Jorge Ricardo Masetti ${ }^{9}$ o publicaciones que reflejaban diversos debates sobre la coyuntura política y la estrategia revolucionaria tales como Pasado y Presente o la experiencia de la revista Che (la cual, bajo el influjo de la Revolución Cubana, se propuso una renovación de la izquierda acercándola, a su vez, a los paradigmas del peronismo ${ }^{10}$ ) fueron algunas de las diversas expresiones surgidas en este contexto de redefiniciones políticas.

Dentro del bagaje teórico del trotskismo, una de las principales expresiones era la denominada corriente "morenista" que, durante el período que comprende esta polémica, se estructuraba en la organización Palabra Obrera. En términos historiográficos, es prácticamente nulo el conocimiento existente sobre esta organización más allá de la producción ligada a la propia corriente $^{11}$ y algunos escasos artículos publicados ${ }^{12}$. Políticamente, uno de los aspectos más relevantes sostenidos por Palabra Obrera, y aún escasamente profundizado como fenómeno, fue el intento de poner en práctica una estrategia de inserción (denominada entrismo) en el movimiento peronista con la intención de radicalizar hacia posiciones de izquierda a sus adherentes. Particularmente, con esta premisa, esta corriente adoptó una filiación pública peronista y desarrolló una militancia fabril en el movimiento obrero en la búsqueda de influir políticamente en su vanguardia. Se trató de una organización cuantitativamente pequeña, con una actividad fabril y sindical sistemática y con presencia en ciertos espacios universitarios en donde desarrolló también una militancia estudiantil.

Bajo los efectos de la Revolución Cubana, desde 1960, Palabra Obrera realizó diversas caracterizaciones que, más allá de resaltar sus diferencias y delimitaciones, se centralizaron en la defensa de este proceso revolucionario. A partir de 1961, esta organización argumentó que Cuba se convirtió en un estado obrero con el componente favorable de tratarse de un gobierno no controlado ni por el aparato comunista ni por una casta burocrática. El análisis se alejaba de la caracterización de "estado obrero degenerado", utilizado por el trotskismo para referirse a aquellos procesos políticos que, iniciados en una revolución obrera, tomaron luego un curso de burocratización a partir del ascenso estalinista. En el Segundo Congreso Nacional de Palabra Obrera, Moreno defendió la posición del surgimiento de un Estado obrero en Cuba como producto de la revolución, pero diferenciándolo del paradigma de la Revolución Rusa en un aspecto: no se trató de un proceso político que contara con una dirección obrera revolucionaria asentada en organismos de democracia obrera como los soviets, sino que estaba dirigido por una conducción pequeño-burguesa apoyada en un ejército revolucionario, campesino, obrero y popular ${ }^{13}$.

\footnotetext{
${ }^{8}$ Califa, Juan Sebastián, "El temprano impacto de la Revolución Cubana en el movimiento estudiantil argentino. El caso de la Universidad de Buenos Aires. 1959-1962”, Nuevo Mundo Mundos Nuevos [En línea], 12-02-2013.

${ }^{9}$ Rot, Gabriel, Los origenes perdidos de la guerrilla argentina: la bistoria de Jorge Ricardo Masetti y el Ejército Guerrillero del Pueblo, Ediciones El Cielo por Asalto, 2000.

10 Tortti, María Cristina, Che. Una revista de la "nueva izquierda" (1960-1961), Buenos Aires, Cedinci Editores, 2013.

${ }^{11}$ González, Ernesto (Coordinador), El trotskismo obrero e internacionalista en la Argentina. Tomo 3: Palabra Obrera, el PRT y la Revolución Cubana. Volumen 1 (1959-1963), Buenos Aires, Editorial Antídoto, 1999.

12 Camarero, Hernán, "Una experiencia de la izquierda en el movimiento obrero. El trotskismo frente a la crisis del peronismo y la resistencia de los trabajadores (1954-1957)", Razón y Revolución, No 3, 1997; Castelo, Fernando, "Todos unidos triunfaremos. El entrismo morenista y sus caracterizaciones", Razón y Revolución, No 6, 2000.

13 "Definición del estado obrero cubano", documento presentado por Nahuel Moreno para el Segundo Congreso Nacional de Palabra Obrera, abril de 1961.
} 
Un año después, en un nuevo escrito referente a esta temática titulado La Revolución Latinoamericana ${ }^{14}$, Moreno esbozó un análisis más afín a los paradigmas teórico-organizativos del proceso revolucionario cubano. Afirmó que esta revolución generó un quiebre político del que se desprendieron distintos fenómenos que modificaron la coyuntura latinoamericana, siendo el principal el cambio en la relación de fuerzas entre el imperialismo y las masas en los países latinoamericanos dado que EEUU carecía de respaldo de conjunto para la aplicación de medidas de agresión a Cuba y que, si bien ello no implicaba una ruptura de los sólidos lazos económicos, políticos y militares que aún mantenía con los diversos gobiernos latinoamericanos, la relación de fuerzas se había alterado. En este aspecto, la Revolución Cubana modificaba el contexto regional porque producía una crisis del imperialismo norteamericano convirtiéndose en el mojón de la segunda independencia del continente ${ }^{15}$.

La afirmación esgrimida acerca de la importancia de este documento como momento de mayor acercamiento teórico a los preceptos de la Revolución Cubana se podría sintetizar en una serie definiciones de peso. En primer lugar, la reivindicación por parte de Moreno de la dirección cubana como la "vanguardia de la revolución latinoamericana" y la identificación de este proceso con la teoría de la revolución permanente de Trotsky, dado que Cuba demostró cómo una transformación política que inicialmente tuvo rasgos democrático-burgueses en su contenido, terminó radicalizándose y convirtiéndose en una revolución socialista con características principalmente agrarias y antiimperialistas. El documento caracterizaba la existencia de diversas etapas que constituían el derrotero revolucionario. Un primer momento encabezado por jóvenes provenientes de la burguesía y de la pequeña burguesía con un desarrollo de determinadas acciones contra el régimen militar que no contaron con el apoyo popular, fue seguido de una etapa en la que amplios sectores de la pequeña burguesía y del campesinado se sumaron al movimiento anti-dictatorial (en principio, conformados como frentes guerrilleros sin coordinación entre sî́. Tras la caída de Batista, se experimentó una etapa marcada por los intentos de la burguesía de frenar el proceso revolucionario y encauzarlo hacia una democracia formal lo que llevó a la corriente liderada por Fidel Castro a apelar al movimiento de masas, principalmente a la clase obrera. Finalmente, ante el frente común de la burguesía contra la revolución y las presiones del imperialismo, la revolución adoptó una serie de medidas radicales tales como, por ejemplo, las milicias armadas, la reforma agraria, el control estatal sobre las grandes empresas industriales extranjeras, entre otras ${ }^{16}$.

Por otro lado, hasta producirse la fallida invasión de Bahía de los Cochinos, la dirección cubana no manifestó un alineamiento a la política de la URSS lo que se convirtió en un elemento reivindicado como positivo para el socialismo internacional por parte de esta corriente política que, en razón de ello, auguraba una aceleración de la crisis de los partidos comunistas ${ }^{17}$.

En otro orden, y en lo que se convirtió seguramente en la concesión de mayor envergadura al paradigma castrista, se afirmó que el campesinado y la pequeña-burguesía podían cumplir en América Latina un papel revolucionario, matizando el carácter obrerista que históricamente el marxismo otorgó al sujeto revolucionario. Ahora bien, más allá de reivindicarse la posibilidad de estos sujetos como actores revolucionarios aptos para la obtención de reivindicaciones democráticas, en el mismo documento también se afirmó que la clase obrera era la única capacitada para cumplir con la transición al socialismo, aunque el proceso fuera iniciado por otros sectores $^{18}$. Este análisis se imbricó con la caracterización de aquellas tareas que, según Moreno, eran fundamentales que el trotskismo tomara como propias en los países latinoamericanos semicoloniales. Tanto en el mencionado escrito como en debates preexistentes, Moreno sostuvo que

\footnotetext{
14 Moreno, Nahuel, La revolución latinoamericana, Buenos Aires, Ediciones PO, marzo de 1962.

${ }^{15}$ Moreno, Nahuel, La revolución latinoamericana... p. 35.

16 Moreno, Nahuel, La revolución latinoamericana... pp. 23-26.

${ }_{17}$ Moreno, Nahuel, La revolución latinoamericana... p. 29 y 36.

${ }^{18}$ Moreno, Nahuel, La revolución latinoamericana... p. 43.
} 
la liberación nacional y la revolución agraria eran consignas y tareas fundamentales en este tipo de países. Ello respondía a que en las semi-colonias, el sujeto obrero era numéricamente escaso y que sectores tales como el campesinado o la pequeña-burguesía poseían mayor peso numérico y político. De allí se desprendía la importancia de las consignas acordes a estos actores que, según esta posición, el trotskismo no podía desconocer o dejar librados a las políticas y a la captación de los partidos comunistas o de los movimientos de tipo nacionalistas y, por ende, era obligación tomarlas como propias más allá de sostenerlas ligándolas a reivindicaciones de corte clasista ${ }^{19}$.

Estas concesiones teóricas al paradigma revolucionario cubano no eliminan su rasgo más relevante a la hora de analizar la existencia de un viraje teórico por parte de esta corriente, a saber, la diferenciación allí establecida entre la lucha armada como parte de la práctica política y la guerra de guerrillas como estrategia revolucionaria. Moreno afirmó que la lucha armada era un método indiscutible, pero que debía llevarse a la práctica de diversas formas, como en la defensa de las huelgas y ocupaciones de fábrica, en los sindicatos campesinos y ocupaciones de tierras, o para contrarrestar el accionar de los grupos reaccionarios, bandas fascistas y rompehuelgas. En este sentido, la guerrilla campesina se convertía solamente en una de las tantas posibilidades de poner en práctica la lucha armada. Por ello, sin negar su viabilidad como opción, se caracterizaba que tal instancia organizativa debía ser considerada como una táctica posible dentro de una estrategia más amplia (la insurrección popular) que admitía diversas variantes de lucha ${ }^{20}$.

En un concepto, que en los años venideros se profundizaría y repetiría en diversas experiencias, se desprendía que, para esta corriente, se convertía en una necesidad no equiparar el concepto de lucha armada (en un marco de inserción de una organización en la lucha de clases y en las acciones de masas) con la guerrilla como táctica específica de lucha, en el sentido de una vanguardia armada que, a partir de acciones aisladas del movimiento de masas, se convertiría en creadora de conciencia. Tal delimitación conceptual se revela determinante para la compresión de las polémicas internas que esta corriente ensayó en estos años y, particularmente, para el acercamiento a las discusiones teóricas, conceptuales y prácticas que guiaron la experiencia peruana aquí reflejada.

\section{El debate Moreno - Pereyra en el contexto insurreccional peruano}

El recientemente reeditado Perú: dos estrategias ${ }^{21}$, da cuenta de las polémicas suscitadas entre la dirección de Palabra Obrera (centralmente, Nahuel Moreno) y la militancia de esta organización enviada al Perú en el marco del ascenso de masas allí iniciado. Como se afirmó, el abordaje de esta compilación documental posee la virtud de dar cuenta del clima de época y del contenido del debate que atravesó a este agrupamiento político argentino a raíz de su estrategia de inserción en el proceso insurreccional peruano. En razón de ello, en el presente apartado se desarrollará el accionar político de este conjunto de militantes radicados en Perú y las polémicas entonces suscitadas y luego reflejadas en Dos estrategias.

La organización argentina Palabra Obrera, acorde a una concepción trotskista de construcción de una corriente internacional de partidos políticos revolucionarios, poseía relaciones políticas con diversas estructuras. De hecho, formaba parte del denominado Secretariado Latinoamericano del Trotskismo Ortodoxo (SLATO), organismo que nucleaba a diversos partidos del continente. Esta coordinación, reunida en abril de 1961, resolvió la necesidad de un vuelco militante a la revolución peruana en ciernes. Ello contextualiza la decisión de Palabra Obrera de sistematizar el envío de cuadros para colaborar con la consolidación del partido peruano y con el movimiento

\footnotetext{
${ }^{19}$ Ediciones Palabra Obrera, No 2, "Latinoamérica y Cuba", 1961 y Moreno, Nahuel, La revolución latinoamericana... p. 42.

20 Moreno, Nahuel, La revolución latinoamericana... pp. 46-47.

${ }^{21}$ Moreno, Nahuel, Perú: dos estrategias..., op. cit.
} 
encabezado por su antiguo miembro Hugo Blanco. A partir de una confluencia de diversos actores, el POR peruano, también miembro del SLATO, pasó a denominarse Frente de Izquierda Revolucionaria (FIR).

En sintonía con las observaciones anteriormente analizadas alrededor de la problemática del sujeto social revolucionario, Moreno reconocía que, en el caso peruano, el campesinado era la vanguardia política y que las acciones acaecidas en el Cuzco tenían rasgos de revolución agraria siendo la posesión de la tierra su principal reivindicación. Resulta ilustrativa, en este sentido, la primera carta reproducida en Dos estrategias escrita por Moreno a Hugo Blanco en abril de 1961 en la que se caracteriza la particularidad de este proceso revolucionario: su punto de partida como una revolución agraria encabezada por el campesinado y no como una revolución obrera (dada la actitud defensiva del proletariado industrial y minero) ${ }^{22}$. Se afirmaba que las dos grandes problemáticas del campesinado peruano eran el acceso a la tierra y el derecho democrático al voto (la imposibilidad de su acceso al sufragio se convertía, según este análisis, en un reflejo de los resabios semi-feudales y de la marcada diferenciación étnica existente). En razón de ello, se planteaba que el desafío de la revolución peruana consistía en ligar estas demandas campesinas con los problemas que inmiscuían a la clase obrera limeña, de la costa y de los grandes centros mineros para potenciar el proceso iniciado a nivel rural. La incapacidad en forjar una célere ligazón entre ambos actores recaía, según este análisis, en la ausencia de un partido revolucionario de peso que pudiera impulsarla ${ }^{23}$.

Rápidamente se desató una polémica entre la dirigencia de Palabra Obrera en Argentina y sus militantes enviados a Perú, especialmente Daniel Pereyra, sobre el modo de inserción y la estrategia a desarrollar. Dado el mencionado desnivel entre una vanguardia campesina en alza y radicalizada y la ausencia de conflictos en las grandes ciudades (donde la problemática predominante era el llamado a elecciones por parte del gobierno), diversos dirigentes del FIR peruano caracterizaron la necesidad de provocar una insurrección previa al proceso electoral y, en esa línea, planificaron la tarea de tomar por asalto el cuartel Gamarra del Cuzco con la intención de repetir la experiencia de la Revolución Cubana del asalto al cuartel Moncada. Para tal objetivo precisaban una suma elevada de fondos por lo que Pereyra y el grupo de Lima encabezado por Martorell asaltaron la sucursal Magdalena del Banco Popular en lo que se convirtió en la primera de las acciones armadas. Tal hecho y el derrotero que estos dirigentes quisieron imprimir al proceso político peruano desataron una fuerte polémica entre Moreno y Pereyra que, si bien tuvo como centro la caracterización de la coyuntura peruana de entonces, conllevaba a su vez el embrión de un debate teórico de fondo en torno a la forma de desarrollo de la lucha armada y a las estrategias a adoptar en cada coyuntura política.

La primera de las polémicas se circunscribió al debate en torno al desarrollo de la lucha armada en tal momento político. Moreno rechazó el golpe al cuartel Gamarra como punto de partida de un proceso insurreccional argumentando que las consecuencias políticas que podrían desprenderse de tal acción eran por demás imprevistas (tales como, por ejemplo, la reacción del gobierno y el aislamiento de la vanguardia revolucionaria) independientemente de la obtención de un éxito desde un punto de vista militar y económico. Se argumentó que la lucha armada debía iniciarse, no a través de una acción de tipo "putchista" sino como parte del desarrollo de las acciones políticas del campesinado que encabezaba el proceso revolucionario. En lugar de dar lugar a una guerrilla y ejecutar un golpe comando, este dirigente rebatió a Pereyra con la necesidad de formar milicias campesinas (motorizadas por el partido, o bien, por un hipotético Frente Único Revolucionario a construir) y no de un modo aislado sino como parte del proceso político y sindical ya abierto como, por ejemplo, en el marco de la toma de tierras y de su defensa. Se argumentaba, como diferencia central entre ambas entidades, que la milicia campesina suponía

22 Moreno, Nahuel, Perú: dos estrategias...p. 24.

${ }^{23}$ Moreno, Nahuel, Perú: dos estrategias...pp. 26-27. 
que el trabajador organizado en tal estructura armada continuaría desarrollando sus labores sindicales y partidarias ${ }^{24}$.

Resulta menester destacar que, en 1964, esta misma polémica fue parte del análisis crítico y más sistemático que hará Moreno sobre los escritos teóricos de Ernesto Che Guevara a quien cuestionó la idea que la guerra de guerrillas era una estrategia indispensable para el campesinado latinoamericano en pugna contra las estructuras feudales. Por ende, rechazó la identificación entre la lucha campesina y la guerra de guerrillas dado que, a lo largo de la historia, diversos conflictos protagonizados por este sujeto social no conllevaron necesariamente la apelación a este método de lucha ${ }^{25}$. En el caso peruano, la utilización de esta metodología suponía un elemento aún más grave: el desprecio por las grandes organizaciones de masas, tales como los sindicatos campesinos, que ya poseía esta vanguardia y que eran ignoradas por la teoría guevarista y hasta caracterizados por ella como un elemento de inhibición de la lucha guerrillera ${ }^{26}$. La aplicación de la guerra de guerrillas como método generaría, a los ojos de este análisis, el efecto contrario: la separación entre una vanguardia revolucionaria armada y las estructuras de masas en las que el campesinado se insertaba y desarrollaba sus luchas. Por ello, en la documentación interna de esta corriente, se repetía un pliego programático que recaía en la necesidad de desarrollar la sindicalización campesina y la ocupación de tierras bajo el control del partido peruano, la preparación de éste para la posibilidad de una insurrección y el inicio de la construcción de un Frente Único Revolucionario con otras fuerzas partidarias ${ }^{27}$.

Colateralmente, un elemento de peso de la polémica acaecida entre Moreno y Pereyra recayó en la equiparación e intento de repetición del proceso revolucionario peruano con el derrotero antes seguido por la Revolución Cubana. Se afirmaba que en Cuba el desarrollo de las guerrillas se inició en un contexto de pasividad y reflujo del movimiento obrero y campesino ante la dictadura de Batista y que ellas lograron el apoyo del movimiento de masas en los momentos finales de la revolución. Contrariamente, Moreno planteaba la necesidad de caracterizar las diferentes condiciones que experimentaba Perú dada la existencia de sindicatos campesinos y ocupaciones de tierras, es decir, la existencia de una lucha abierta con las masas en ascenso y un desarrollo ya existente de las organizaciones de base ${ }^{28}$.

Un elemento teórico de importancia desarrollado por Moreno en su correspondencia con Pereyra recayó en la necesidad de profundizar el embrionario poder dual iniciado. Este concepto fue utilizado por Trotsky para definir aquellas situaciones prerrevolucionarias en las que la clase trabajadora, llamada a implantar el nuevo sistema social, si bien no era aún dueña del país, reunía de hecho en sus manos una parte considerable del poder del Estado mientras que su aparato oficial continuaba aún en manos de sus antiguos detentadores ${ }^{29}$. En su aplicación a la realidad peruana, Moreno planteó en diversas cartas que el ascenso del movimiento de masas, prioritariamente campesino, dio forma a embriones de poder dual mediante la ocupación de tierras por parte de las comunidades y los sindicatos campesinos. En ese sentido, la principal tarea que debía impulsar la vanguardia revolucionaria era la profundización de la toma de tierras bajo la administración de los sindicatos campesinos y la formación de milicias armadas para su defensa ${ }^{30}$. En este marco, Moreno le cuestionó a Pereyra minimizar las zonas campesinas en beneficio de las urbanas, no haber aprendido el quechua como medio de comunicación con buena parte de la población campesina, menospreciar el papel del partido en la organización de la

\footnotetext{
${ }^{24}$ Moreno, Nahuel, Perú: dos estrategias...pp. 42-43.

25 Moreno, Nahuel, Dos métodos frente a la revolución latinoamericana. ¿Lucha guerrillera o lucha obrera y de masas?, Buenos Aires, Biblioteca Virtual del CITO, 1964, pp. 3-4.

${ }^{26}$ Moreno, Nahuel, Dos métodos frente... p. 17.

${ }^{27}$ Boletín de Palabra Obrera, "Serie B: Latinoamérica. Proyecto de informe latinoamericano de actividades", 1963 , p. 2 .

${ }^{28}$ Moreno, Nahuel, Dos métodos frente... pp. 35-36.

29 Trotsky, León, Historia de la Revolución Rusa, Tomo 1, Buenos Aires, Editorial Antídoto, 1997, p. 196.

${ }^{30}$ Moreno, Nahuel, Perú: dos estrategias...p. 39 y 58.
} 
sindicalización y de las ocupaciones de tierras y proseguir con una estrategia de tipo "putschista" marginada de estos embriones de doble poder ${ }^{31}$. Ello contrarrestaba con la visión sostenida sobre el accionar del dirigente campesino Hugo Blanco de quien el "morenismo" reivindicó su contribución al desarrollo del poder dual a partir de la consolidación de las milicias armadas de los sindicatos campesinos, la toma de prisioneros y rehenes para luego ser canjeados, la ejecución de agentes de los gamonales (terratenientes) y la reforma agraria realizada por los mismos organismos de base ${ }^{32}$.

Un último elemento de debate recayó en la necesidad, o no, de que una estructura revolucionaria se posicionara ante la apertura electoral en ciernes. En relación con ello, Moreno cuestionó a la militancia enviada a Perú que el tipo de acciones armadas que pretendían desarrollar daba por sentado que las masas (tanto urbanas como rurales) ya habían agotado y dejado atrás una expectativa positiva con respecto a esta vía de participación. En contraposición, se planteaba que la táctica debía centrarse en dos aspectos. Por un lado, no ignorar el proceso electoral y las expectativas que éste generaba en la población a través de la reivindicación de un frente electoral entre la federación campesina, las centrales obreras y los diversos partidos autoproclamados revolucionarios. Por otro lado, darle continuidad al desarrollo del poder dual en el campo porque ello sería la garantía de que el campesino no fuera absorbido por una etapa democrática-formal sino que profundizara las herramientas propias de una democracia revolucionaria ${ }^{33}$.

Lo recientemente descripto se imbricaba directamente con la crítica que Moreno realizaba en cada uno de los escritos enviados a Perú sobre la necesidad de consolidación de un partido revolucionario. En esta línea, se cuestionaba a la militancia de Palabra Obrera inserta en Perú una supuesta perspectiva de reemplazo del partido con las acciones independientes de la vanguardia revolucionaria. Desde este enfoque, la necesidad de un partido revolucionario con peso debía tener como objeto centralizar y organizar las acciones, inorgánicas y caóticas, del movimiento de masas $^{34}$.

La facción en Perú encabezada por Pereyra prosiguió con una estrategia de desarrollo de acciones armadas con el objetivo principal de recaudar fondos para profundizar el ascenso revolucionario y las futuras iniciativas. En abril de 1962, un comando asaltó la sucursal del Banco de Crédito de Miraflores en el marco de errores organizativos que desembocaron en la identificación por parte de la policía de los distintos militantes participantes de la acción. El resultado final fue la detención de Pereyra y de otros militantes lo que trajo aparejado la persecución al FIR tras su identificación como responsable político del asalto. El propio Moreno fue detenido en Bolivia (en donde se encontraba coordinando el apoyo a Hugo Blanco) tras un pedido de extradición del gobierno peruano como responsable intelectual del asalto. Por su parte, el movimiento campesino de Blanco quedó política y geográficamente aislado y, finalmente, este dirigente fue detenido junto a importantes referentes de las luchas agrarias. Tras un proceso judicial, Blanco fue condenado a muerte, aunque una masiva y resonada campaña internacional logró la conmutación de esta pena y, luego, obtener la amnistía. En una posterior combinación de represión y concesiones sociales que incluyeron la puesta en práctica de una política agraria, el gobierno peruano logró detener este proceso de ascenso y agitación campesina.

\section{Resignificar la experiencia a través de la memoria}

Más de medio siglo después de acaecidos los hechos antes narrados, recientemente el propio Daniel Pereyra publicó sus memorias políticas ${ }^{35}$. Con un estilo que se enmarca en el género

\footnotetext{
${ }^{31}$ Moreno, Nahuel, Perú: dos estrategias...pp. 55-56.

32 Boletín de palabra obrera, "Serie B: Latinoamérica..." Op. Cit., p. 6

${ }_{33}$ Moreno, Nahuel, Perú: dos estrategias...pp. 46-48.

${ }^{34}$ Moreno, Nahuel, Perú: dos estrategias...pp. 105-106.

${ }^{35}$ Pereyra, Daniel, Memorias... Op. Cit.
} 
autobiográfico, este trabajo se transforma en un insumo factible de ser tenido en cuenta más allá de las lógicas advertencias que supone su abordaje, siendo la observación central el tratarse de reflexiones que son resultado de balances realizados a lo largo de décadas posteriores a los sucesos descriptos. En ese sentido, al igual que ocurre con el insumo de la historia oral, se trata no solo de la narración de los hechos experimentados sino también, simultáneamente, de cómo su mismo protagonista resignificó tales sucesos a lo largo de los años y las diversas experiencias vividas con posterioridad a éstos.

En las memorias, no resulta escaso el espacio dedicado a la narración del proceso vivido en el Perú en los tempranos años sesenta pero sí insuficiente en cuanto a las respuestas y argumentaciones dadas alrededor de las polémicas surgidas a lo largo de esta experiencia. El escrito de Pereyra denota dos preocupaciones centrales: rebatir la concepción de haber sostenido un accionar "putschista" ajeno al movimiento de masas y, simultáneamente, sugerir que la dirección de Palabra Obrera decidió una línea de intervención en Perú afín a las acciones armadas inicialmente realizadas que, una vez efectuadas, fue revertida y cuestionada.

Las memorias de Pereyra dan cuenta de la decisión, una vez inserto en el Perú, de desarrollar un equipo militar dentro del partido que resolviera los problemas económicos de la organización dadas las cuantiosas tareas necesarias de efectuar. Con ese objetivo, se justifica el asalto a la sucursal Magdalena del Banco Popular, caracterizada como una operación exitosa en lo militar pero fallida en lo económico dada la escasez de la recaudación obtenida lo que obligaba a la realización de otras acciones similares ${ }^{36}$. En otro orden, se rechaza que uno de los objetivos de la organización peruana fuera copar el cuartel Gamarra del Cuzco emulando el paradigma cubano con la toma del Moncada. Pereyra esgrime que tal plan nunca existió y que el interés en dicho cuartel recaía simplemente en el objetivo de forjar una militancia política entre los soldados conscriptos que allí residían dado que, mayoritariamente, se trataba de jóvenes de ascendencia campesina que en su estadía en el ejército habían aprendido a manejar armas y se habían alfabetizado sufriendo una importante discriminación étnica y de clase por parte de sus superiores $^{37}$. Por su parte, se argumenta que el fallido asalto a la sucursal del Banco de Crédito de Miraflores tuvo una importante planificación y entrenamiento previo, pero que la identificación de sus militantes en el momento de la acción obligó a un abrupto cambio de planes ${ }^{38}$.

En relación con este accionar, la respuesta que Pereyra desarrolla rebatiendo la acusación de desviaciones "putschistas" se circunscribe a argumentar que, para desarrollar un trabajo político al interior del movimiento de masas, la obtención de fondos resultaba fundamental. Sus Memorias esgrimen que consolidar la toma de tierras (con los consecuentes enfrentamientos con los terratenientes y las fuerzas policiales), incrementar el armamento del campesinado para sostener este accionar, etcétera, precisaba inevitablemente de recursos económicos ${ }^{39}$. Se desprende entonces de esta explicación que las acciones militares no se encontraban desligadas de la militancia dentro del movimiento social existente sino en función de ella.

El elemento más polémico de las Memorias se vincula con la relación existente entre la dirección de Palabra Obrera en la Argentina y su militancia enviada a Perú. Se interpreta del relato de Pereyra que, inicialmente, las acciones a realizar por parte de la organización peruana poseían el aval de la conducción argentina y de la coordinación internacional encarnada en el SLATO pero que, una vez emprendidas, se produjo por parte de Moreno el inicio de las acusaciones antes referidas sobre desviaciones "putschistas" y "aventureras" 40 . Por otro lado, Pereyra esgrime que la presión del campesinado y del movimiento de Hugo Blanco llevó a la urgencia por la obtención

\footnotetext{
36 Pereyra, Daniel, Memorias... pp. 108-109.

37 Pereyra, Daniel, Memorias... pp. 114-115.

38 Pereyra, Daniel, Memorias... p. 125.

39 Pereyra, Daniel, Memorias... p. 121.

${ }^{40}$ Pereyra, Daniel, Memorias... p. 160.
} 
de fondos y que, por parte de la dirección de Palabra Obrera, no existieron lineamientos claros sobre cómo actuar lo que generó una situación de aislamiento. Incluso, se argumenta que no existió ayuda material o legal del partido argentino durante los años de detención en el Perú tras el fracaso del asalto a la sucursal bancaria ${ }^{41}$.

Resignificar las experiencias sostenidas más de medio siglo atrás supone otorgarles un sentido impregnado por los balances y las vivencias que acontecieron desde entonces. A su vez, el estilo ensayístico de las Memorias como género dificulta la realización de un análisis historiográfico minucioso porque se trata de dos registros complejos de equilibrar. No obstante, es factible desprender de las Memorias de Pereyra algunas reflexiones e interrogantes que permiten complejizar el debate alrededor de la estrategia aplicada en Perú.

En primer lugar, Pereyra polemiza contra un trabajo coordinado por un histórico dirigente de esta corriente política, Ernesto González, publicado en el año $1999^{42}$. En esta producción, se relatan los sucesos de Perú centralmente a través de la documentación que recientemente se reeditaría en el ya citado Perú: Dos estrategias. Más allá de resultar llamativa que no mediara ningún tipo de respuesta política en los quince años que transcurrieron entre dicho trabajo y la aparición de las Memorias, más notoria aún es la ausencia de otro tipo de documentación contemporánea a los hechos que contrarreste las versiones sostenidas por las diversas producciones mencionadas. En su lugar, Pereyra apela al formato del ensayo, o bien se apoya en otro tipo de fuentes secundarias $^{43}$. La represión y el encarcelamiento sufrido por este dirigente podría ser el motivo de ausencia de documentación en su poder y por ende su no inclusión en los testimonios, no obstante lo cual, resultaría relevante conocer si ésta es la causante de tal ausencia.

Un elemento que reviste interés y que no se desprende de las Memorias recae en explicar por qué Pereyra, luego de su encarcelamiento en Perú y (según se desprende de su relato), tras no haber recibido la colaboración de su organización, al retornar a la Argentina se reintegró a la militancia en esta corriente. Sus Memorias narran la vuelta al país y su reinserción en Palabra Obrera en el momento en que se producía la inminente fusión con el Frente Revolucionario Indoamericano y Popular (FRIP) de los hermanos Santucho para dar origen, en 1965, al Partido Revolucionario de los Trabajadores (PRT). Resultaría reveladora una narración por parte de Pereyra de su retorno a la Argentina y la vuelta a la militancia en esta corriente (en la que se mantuvo hasta 1968) tras las profundas diferencias antes experimentadas.

Finalmente, se destaca como curiosidad que ciertas aseveraciones que Pereyra realiza en sus Memorias encuentran dejos de diferenciación con su propia producción previa, particularmente con respecto a su trabajo Del Moncada a Chiapas $^{44}$. Dicho texto, publicado en 2011, es un relevo, país por país, del accionar guerrillero en América Latina a lo largo del siglo XX. Al referirse a la experiencia peruana, de la cual fue parte, Pereyra afirma que la idea de impulsar la lucha armada era asumida por la organización peruana sin demasiada claridad en cuanto a la forma que ella debía tomar, que influyó (en la celeridad por realizar tales acciones) la constante presión y demanda de armas por parte del campesinado y que, ante el inicio de la represión, el FIR quedó afectado dada su inexperiencia y debilidad ${ }^{45}$. Resulta llamativo el contraste con las argumentaciones sostenidas en las posteriores Memorias en donde se esgrime tanto una preparación técnica para la realización de dichas acciones como una claridad en cuanto a los objetivos que ellas conllevaban.

\footnotetext{
41 Pereyra, Daniel, Memorias... pp. 168-169.

${ }^{42}$ González, Ernesto (Coordinador), El trotskismo obrero e internacionalista..., op. cit.

${ }^{43}$ Coggiola, Osvaldo, Historia del trotskismo en Argentina y América Latina, Buenos Aires, Ediciones RyR, 2006.

${ }_{44}$ Pereyra, Daniel, Del Moncada a Chiapas. Historia de la lucha armada en América Latina. Buenos Aires, Ediciones RyR, 2011.

${ }^{45}$ Daniel, Del Moncada a Chiapas... pp. 156-157.
} 
Como se mencionó anteriormente, el restante insumo que relata esta experiencia es un reciente documental sobre la vida de Nahuel Moreno $^{46}$ en el que se dedica un destacado espacio al accionar de su corriente en el Perú. La estética de este material audiovisual se circunscribe a una estructura narrativa basada en la sucesión de testimonios de los protagonistas sin mediar un relato explicativo que trascienda a los mismos. En lo pertinente a la polémica suscitada entre Moreno y Pereyra se destacan el testimonio del propio Hugo Blanco, quien relata su proceso formativo en la militancia en la Argentina como parte de Palabra Obrera y, luego, su inserción en el campesinado cuzqueño dado que traía consigo, de su experiencia en esta organización, la premisa de inmiscuirse en aquel sujeto que estuviera en la vanguardia. A su vez, Blanco afirma que su detención fue una consecuencia del accionar armado impulsado por el equipo militar de Pereyra y que él desconocía el plan de asalto a una sucursal bancaria dado que, de haberlo sabido, hubiera manifestado su oposición por tratarse de una acción aislada del movimiento de masas. Se destacan también testimonios de otros referentes peruanos tales como Leoncio Bueno (quien participó de las expropiaciones bancarias junto a Pereyra) y Enrique Fernández Chacón (un importante dirigente político-sindical de Perú en los años sesenta y setenta).

Paralelamente, el documental incorpora un breve testimonio del propio Daniel Pereyra, quien reproduce afirmaciones similares a las vertidas en sus Memorias y de otros dirigentes de peso de la corriente con posiciones antagónicas sobre este proceso. En ese sentido, se contrapone el relato de Horacio Lagar (quien justifica la línea de acción llevada a cabo por Pereyra en Perú como parte de una actitud sostenida en ese momento por la corriente política "morenista") con el testimonio de Pedro Pujals, quien afirma que Pereyra desconoció la directiva de consolidar un partido revolucionario trotskista en Perú y fortalecer un apoyo político al movimiento encabezado por Hugo Blanco. No obstante los valiosos testimonios, dada la propia estructura y elección estética, el documental se priva de extraer conclusiones o análisis de los sucesos reflejados ${ }^{47}$.

\section{Conclusiones}

A modo de cierre, es menester aclarar que la polémica sostenida entre la dirección de Palabra Obrera y el grupo encabezado por Daniel Pereyra no fue excepcional en la coyuntura abierta a principios de los años sesenta. Otra relevante discusión, prácticamente simultánea con la anterior, se produjo entre los años 1963-1964 entre Moreno y Ángel "Vasco" Bengochea, a partir del viaje de este último a Cuba junto a otros militantes de Palabra Obrera y su retorno a la Argentina adscribiendo a la estrategia guevarista y a su aplicación en el país, iniciativa que terminaría con la trágica muerte de este referente ${ }^{48}$. Los debates dentro de Palabra Obrera constituyeron los antecedentes directos de la polémica que, en 1968, protagonizaron Moreno y Mario Roberto Santucho y que desembocó en la ruptura del PRT ${ }^{49}$. Tal polémica presentó mayores matices, argumentaciones y ejemplificaciones que las mencionadas hasta el momento. Sin embargo, los embriones teóricos de tal discusión, como se pretendió ejemplificar, ya se hallaban presentes con anterioridad. Al mismo tiempo, lo destacable recae en que los mismos actores que se unirán a la corriente "morenista" tras producirse estos debates como, por ejemplo, los integrantes del FRIP de Santucho, protagonizaron luego una polémica con esta corriente con rasgos similares en la que

\footnotetext{
${ }^{46}$ El trotskismo bárbaro...

${ }^{47}$ Una curiosidad que refleja el documental es la incorporación de imágenes de una película peruana titulada Abisa a los compañeros (sic), estrenada en 1980 bajo la dirección de Felipe Degrogori. Se trata de una adaptación cinematográfica de la novela de 1976 Abisa a los compañeros, pronto de Guillermo Thorndike, quien también escribió el guión de la película.

48 Mangiantini, Martín, El trotskismo..., op. cit.; Nicanoff, Sergio y Castellano, Axel, Las primeras experiencias guerrilleras en la Argentina. La bistoria del "Vasco" Bengochea y las Fuerzas Armadas de la Revolución Nacional, Buenos Aires, Ediciones del Centro Cultural de la Cooperación, 2006; Bengochea, Ángel, La guerra del pueblo [Conferencia de 1962], Montevideo, Corporación Gráfica, 1970.

49 Mangiantini, Martín, El trotskismo..., op. cit.
} 
se reiterarían diversos elementos de estas discusiones. En este sentido, es digno de mención que los cuantiosos aportes que abordaron el derrotero del PRT (mayoritariamente, desde su fractura de 1968 tomando como punto de partida la conformación del denominado PRT-El Combatiente y, luego, PRT-ERP ${ }^{50}$ ), omitieron la existencia de este antecedente que conllevó premisas y elementos de debate similares a los sostenidos años después dentro de esta misma corriente.

Simultáneamente, el debate aquí reflejado es factible de insertarse dentro de la discusión historiográfica-conceptual alrededor de la existencia de una "Nueva Izquierda" surgida en los años sesenta. En relación con ello, el abordaje de una organización como Palabra Obrera, inmersa a su vez, en una polémica sobre la estrategia armada da cuenta del clima de época y permite la reflexión sobre esta categoría. Determinados aportes sobre la militancia revolucionaria utilizaron un criterio de identificación y subdivisión entre una "Izquierda Tradicional" (IT) representada por aquellos partidos políticos de tradición y estructura marxista-leninista y la presencia de una "Nueva Izquierda" (NI) marcada por la aparición de flamantes actores, especialmente las organizaciones político-militares ${ }^{51}$. En ocasiones, se afirmó que aquellas estructuras pertenecientes a la NI presentaron una mayor democracia interna y una praxis más horizontal que los partidos tradicionales. En otras producciones, se identificó a la IT como una corriente reformista, pacifista y electoralista mientras que la NI produjo un nuevo significado y valorización del uso de la violencia. La apelación a una NI también remitió a aquellas estructuras que pugnaron por la fusión de un ideario marxista con otras tradiciones políticas como el peronismo, o bien, a las organizaciones que, si bien no asumieron la lucha armada, no desdeñaron el papel de la violencia como modo de alcanzar la transformación socialista ${ }^{52}$. Bajo estas premisas, es válido preguntarse en qué categoría colocar a la corriente aquí desarrollada. Manteniendo una estructura interna acorde al paradigma de construcción leninista y a los preceptos del centralismo democrático, tuvo como elemento central la búsqueda de inserción en un proletariado mayoritariamente peronista adoptando públicamente esa filiación como estrategia de penetración en la clase. Al mismo tiempo, la polémica aquí reflejada da cuenta del impacto de la lucha armada y de la necesidad de los nuevos sentidos que la violencia política adoptó en este derrotero. Sobre esta base, es válido preguntarse entonces sí, más allá de las continuidades organizativas propias de la IT, la experiencia de Palabra Obrera no es factible de identificar como un ejemplo matizado de la aparición de la NI de esos años.

En razón de lo antes dicho, el presente trabajo pretendió dar cuenta de distintos fenómenos. En primer lugar, ilustrar el impacto que el paradigma revolucionario cubano supuso en una organización trotskista argentina en los años posteriores a su triunfo. Es sabido que el guevarismo ejerció una influencia teórica y metodológica en toda América Latina y que la reproducción de este paradigma fue una constante en los años posteriores a su triunfo. No obstante, también existe la suposición que, para las corrientes trotskistas, este fenómeno no implicó un viraje determinante dada la supervivencia de un paradigma marxista-leninista desde el punto de vista organizativo y de la estrategia insurreccional de carácter obrerista para la transformación revolucionaria de la sociedad. Sin embargo, tomando un pequeño ejemplo como la experiencia

\footnotetext{
${ }^{50}$ Carnovale, Vera, Los combatientes. Historia del PRT-ERP, Buenos Aires, Siglo XXI, 2011; Pozzi, Pablo, Por las sendas argentinas. El PRT-ERP, la guerrilla marxista, Buenos Aires, Imago Mundi, 2000; Weisz, Eduardo, WEISZ, Eduardo, El PRT-ERP: Nueva Izquierda e Izquierda Tradicional, Buenos Aires, CCC, 2004.

${ }^{51}$ Hilb, Claudia y Lutzky, Daniel, La nueva iqquierda argentina: 1960-1980 (Política y violencia), Buenos Aires, CEAL, 1984; Zolov, Eric, 'Expandiendo nuestros horizontes conceptuales: El pasaje de una 'vieja' a una 'nueva izquierda' en América Latina en los años sesenta", Revista Aletheia, Vol. 2, N 4, 2012.

52 Terán, Oscar, Nuestros años sesentas: La formación de la nueva izquierda intelectual en la Argentina, 1955-1966, Buenos Aires, Punto Sur, 1991; Tortti, María Cristina "Protesta social y ‘Nueva Izquierda' en la Argentina del Gran Acuerdo Nacional", en Pucciarelli, Alfredo (Coord.), La primacía de la política. Lanusse, Perón y la Nueva Izquierda en tiempos del GAN, Buenos Aires, Eudeba, 1999.
} 
militante en Perú de la organización Palabra Obrera, se evidencia que, al interior de la izquierda latinoamericana, el triunfo revolucionario cubano supuso redefiniciones, reorientaciones y debates que se mantuvieron a partir de esa década y que permanecerían durante un tiempo considerable.

En otro orden, vale una última reflexión de carácter historiográfico. Más allá de las numerosas investigaciones gestadas desde la investigación profesional, tanto las reediciones de documentación como las publicaciones de memorias militantes o la realización de otro tipo de insumos como los materiales audiovisuales documentales, son una clara demostración de un campo de estudio aún no agotado. Desde el retorno al sistema democrático en 1983, se experimentó en el campo historiográfico argentino un marcado interés por el estudio y la reflexión alrededor de la violencia política dinamizada durante los años preexistentes al golpe cívico-militar acaecido en 1976, la lucha armada como estrategia revolucionaria y la conformación y derrotero de aquellas organizaciones simultáneamente políticas y militares (OPM). Sin embargo, el debate aquí descripto alrededor de la realidad peruana que, a su vez, involucró a una organización argentina da cuenta de la enorme cantidad de aristas y matices que estas temáticas poseen y el arduo y extenso campo de estudio que aún encuentra una inmensa oportunidad de indagaciones factibles de descubrir y profundizar historiográficamente. 